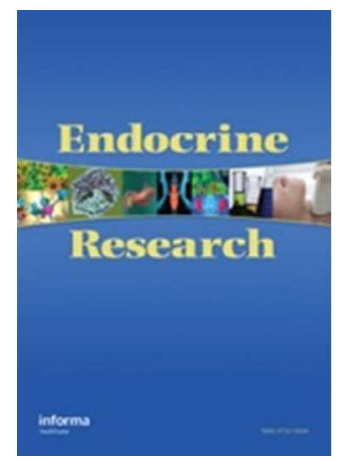

\title{
Hormone-deprived serum impairs angiogenic properties in human endothelial cells regardless of estrogens
}

\begin{tabular}{|r|l|}
\hline Journal: & Endocrine Research \\
\hline Manuscript ID & LERC-2015-0235.R1 \\
\hline Manuscript Type: & Original Paper \\
\hline Date Submitted by the Author: & n/a \\
\hline Complete List of Authors: & $\begin{array}{l}\text { Vanetti, Claudia; University of Milano, Medical Biotechnology and } \\
\text { Translational Medicine } \\
\text { Vicentini, Lucia; University of Milano, Medical Biotechnology and } \\
\text { Translational Medicine } \\
\text { Cattaneo, Maria Grazia; University of Milano, Medical Biotechnology and } \\
\text { Translational Medicine }\end{array}$ \\
\hline Keywords: & $\begin{array}{l}\text { endothelial cells, hormone-deprived serum, sex steroids, cell growth, in } \\
\text { vitro angiogenesis }\end{array}$ \\
\hline
\end{tabular}

\section{SCHOLARONE ${ }^{\text {IM }}$ \\ Manuscripts}




\author{
Hormone-deprived serum impairs angiogenic properties in human endothelial \\ cells regardless of estrogens \\ Claudia Vanetti, Lucia M. Vicentini and Maria Grazia Cattaneo* \\ Department of Medical Biotechnology and Translational Medicine, Università degli Studi di \\ Milano, Via Vanvitelli 32, 20129 Milano, Italy \\ *Corresponding author: mgrazia.cattaneo@unimi.it
}




\begin{abstract}
Introduction. In vitro studies on hormone biological activities are commonly performed on cells cultured in nominally hormone-free media consisting of phenol-red free media supplemented with charcoal-stripped serum. These media are largely used in almost all cell types, including endothelial cells. Methods. Cell number and metabolic activity were measured with standard methods. Angiogenesis was evaluated in a 3-D spheroid sprouting assay. Results. When we compared human umbilical vein endothelial cells (HUVECs) cultured in standard conditions (199 medium supplemented with normal serum) with HUVECs grown in the hormone-free medium (phenol red-free 199 medium supplemented with charcoal-stripped serum), we found that cells stop to grow in the absence of hormones. Notably, neither $17-\beta 2$ estradiol nor dihydrotestosterone reversed this inhibition. Moreover, the presence of the charcoal-stripped serum was sufficient to abrogate the ability of HUVECs to sprout in a 3-D spheroid assay, thus affecting a functional property of endothelial cells. Conclusions. Our results suggest that one or possible more substances removed by stripping procedure from serum and different from sex hormones are crucial for the maintenance of in vitro endothelial cell distinctive properties. Therefore, caution should be used when endothelial cells are studied in media containing the charcoal-stripped serum.
\end{abstract}

Keywords: endothelial cells; hormone-deprived serum; sex steroids; cell growth; in vitro angiogenesis 


\section{Introduction}

Atherosclerosis and cardiovascular diseases $(C V D s)^{1}$ are classical examples of diseases where sex/gender differences have been described. A significant body of epidemiological evidence suggests that CVDs are less prevalent in women than men until midlife, and the female advantage in younger women has been attributed to estrogens, which are lost with menopause $(1,2)$. Since the earliest event in the onset of atherosclerosis and CVDs is endothelial dysfunction, i.e. a reduced release of nitric oxide coupled with an increase in reactive oxygen species in the vascular wall $(3,4)$, many studies have been focused on endothelium, showing a protective role for estrogens in both in vivo and in vitro models $(5,6)$ where estrogens are able to improve endothelial cell (EC) functions mainly through their ability of increasing transcription and activation of the endothelial Nitric Oxide Synthase (eNOS) (7-9).

To better study the influence of estrogens on metabolic properties of ECs, we started some pilot experiments in human umbilical vein ECs (HUVECs) by using an addback approach typically adopted to assess in vitro hormone biological activities. Essentially, in these reconstitution experiments, sex hormones are added to cells cultured in nominally hormone-free media consisting of phenol-red free media supplemented with charcoal-stripped (CS) serum. Phenol red is avoided due to its estrogenic activity (10) while the stripping procedure depletes the concentration of steroid hormones in serum $(11,12)$. Surprisingly, when we compared HUVECs cultured in standard condition or in the hormone-free medium, we found that cells stop to grow in the absence of hormones, and neither 17- $\beta 2$ estradiol (E2) nor dihydrotestosterone (DHT) reversed this effect. In addition, the presence of CS serum abrogated the ability of HUVECs to sprout in a 3dimensional (3-D) spheroid assay, thus affecting a distinctive property of ECs. Our results

\footnotetext{
${ }^{1}$ Abbreviations: bFGF, basic Fibroblast Growth Factor; ChM, charcoal medium; CS, charcoal-stripped; CVD, cardiovascular disease; DHT, dihydrotestosterone; E2, 17- $\beta 2$ estradiol; ECs, endothelial cells; eNOS, endothelial Nitric Oxide Synthase; HUVEC, human umbilical vein endothelial cell; SM, standard medium; VEGF, Vascular Endothelial Growth Factor.
} 
suggest that one or more substances removed from serum by stripping procedure (and different from sex hormones) are crucially required for HUVEC growth and sprouting. Therefore, caution should be used in interpreting results when ECs are studied in CS serum-containing media.

\section{Materials and methods}

\section{Cell cultures}

HUVECs were isolated from freshly derived umbilical cords by collagenase digestion as described by Jaffe et al. (13). Cells were routinely grown in 199 medium supplemented with $20 \%$ fetal bovine serum (FBS), $25 \mu \mathrm{g} / \mathrm{ml}$ endothelial cell growth supplement (ECGS), and $50 \mu \mathrm{g} / \mathrm{ml}$ heparin, and used at passages 1-3. ECGS is an extract of bovine neural tissue containing growth factors for mammalian ECs (Sigma Aldrich, product number E2759). Notably, we always used HUVECs pooled from two or more donors to minimize the variability associated with cells derived from a single newborn donor. Umbilical cords were donated anonymously after informed consent according to national ethical legislation. Charcoal stripping of FBS was performed following standard protocols (11). All the experiments were performed on cells plated on $0.1 \%$ gelatin-coated surfaces. When sex hormones were tested, a corresponding concentration of vehicle (ethanol) was added to control samples.

\section{Cell metabolism assays}

Cell metabolism was assessed by the MTT tetrazolium reduction assay and by measuring the total cellular ATP with a CellTiter-Glo ${ }^{\circledR}$ Luminescent assay (Promega). All assays were performed according to the manufacturer's instructions on HUVECs plated at a density of $2 \times 10^{4}$ cells/well in 96-well microplates. Optical density at $570 \mathrm{~nm}$ (for MTT) and luminescence (for ATP) were measured by using a multi-plate spectrophotometer $\left(\right.$ Victor $^{\mathrm{TM}}$, PerkinElmer). All the experiments were run in triplicate.

\section{Evaluation of cell number and viability}

Cell number and viability were assessed by the trypan blue exclusion test. Quantification of apoptosis/necrosis was performed by the Annexin V-FITC conjugate and propidium 
iodide (PI) staining (Abcam) followed by fluorescence activated cell sorting (FACS) performed with a FACScalibur flow cytometer equipped with a $488 \mathrm{~nm}$ argon laser (Becton Dickinson). The collected data were evaluated by Cell Quest software.

\section{Three-dimensional (3-D) spheroid sprouting assay}

EC spheroids of a defined cell number were embedded into collagen gels in the presence of $25 \mathrm{ng} / \mathrm{ml}$ VEGF as previously described $(14,15)$. Spheroid-containing gels were incubated at $37^{\circ} \mathrm{C}$ in $5 \% \mathrm{CO}_{2}$, and $24 \mathrm{~h}$ later images were acquired with a phase-contrast microscope (10x objective magnification, Olympus U-CMAD3) equipped with an Olympus digital camera. In-gel angiogenesis was quantified by measuring the number and length of all of the capillary-like sprouts originating from individual spheroids using the National Institute of Health (NIH) Image J program. At least 10 randomly selected spheroids per experimental group were measured in each experiment.

\section{Reagents and Antibodies}

All tissue culture reagents were from Euroclone SpA except FBS (PAA Laboratories), ECGS and heparin (Sigma Aldrich). Charcoal, dextran T-70, MTT, trypan blue and methylcellulose (product number M0512) were from Sigma Aldrich; rat tail collagen I from Serva; recombinant human VEGF 165 from Peprotech; E2 and DHT from Cayman Chemical.

\section{Statistical procedures}

Unless otherwise indicated, data are the mean \pm s.e.m of at least 3 independent experiments. Statistical significance was determined by unpaired Student's $t$-test or oneway analysis of variance (ANOVA) followed by Bonferroni's multiple comparison test using the GraphPad Prism version 5.00 software.

\section{Results}

\section{Effects of hormone deprivation on metabolic activity and cell number}

A crucial issue in endothelial patho-physiology concerns estrogens and their involvement in the sex-related incidence of cardiovascular pathologies $(1,2)$. To study the contribution of estrogens to in vitro EC behavior, we compared metabolic properties of HUVECs grown in a Standard Medium (199 medium w/phenol red supplemented with 10\% normal FBS, 
SM) or in a nominally estrogen-free medium (199 medium w/out phenol red supplemented with $10 \%$ CS-FBS, Charcoal Medium, ChM) commonly used for in vitro studies on hormone activities. HUVECs were cultured for $48 \mathrm{~h}$ in SM or ChM, then fresh media were added, and metabolic activities were measured after a further $48 \mathrm{~h}$-incubation. In the absence of estrogens, MTT absorbance (Fig. 1A) and ATP levels (Fig. 1B) were significantly reduced in comparison to SM. To elucidate if decreases in MTT and ATP were merely dependent on a failure in metabolic activity or were vice versa consequent to a reduced cell growth, the number of HUVECs in the different experimental conditions was measured and a significant reduction in cells cultured in ChM was found (Fig. 1C). However, the loss in cell number did not depend on ChM-induced apoptosis and/or necrosis. Their quantification by annexin V-conjugated FITC and PI staining followed by FACS analysis did not show any significant difference neither in the apoptotic index nor in the percentage of necrotic cells (Fig. 1D).

\section{Sex hormones do not reverse the decrease in metabolic activity and cell number}

By using an add-back approach, we tested if estrogens were able to counteract the inhibitory effects observed in HUVECs cultured in ChM. The addition of $17-\beta 2$ estradiol (E2, $1 \mathrm{nM}$ ) for the last $48 \mathrm{~h}$ of incubation left unaffected the ChM-induced decrease in MTT absorbance (Fig. 2A). Super imposable results were obtained by measuring the total cellular ATP (Fig. 2B) and the number of cells (Fig. 2C). Since the stripping procedure removes sex hormones other than E2 from serum, we checked the effect of ChM supplementation with dihydrotestosterone (DHT, $1 \mathrm{nM})$ and found that it did not reverse the decrease in MTT absorbance (Fig. 2D). Likewise, the simultaneous addition of E2 and DHT (both at a $1 \mathrm{nM}$ concentration) left unaffected the reduced MTT absorbance (Fig. 2D). Also the treatment with higher concentrations of $E 2$ and/or $\mathrm{DHT}$ (10 $\mathrm{nM}$ ) did not modify these results (data not shown). On the contrary, HUVECs were able to fully recover their metabolic activity when SM was added instead of hormones for the last $48 \mathrm{~h}$ of incubation (Fig. 2E). All together, these results demonstrate that HUVECs underwent a significant decrease in cell number (and consequently in metabolic activity) without any 
apparent cell death when cultured in a phenol red-free medium supplemented with CSFBS. Importantly, this reduction was independent of the presence of E2 and/or DHT regardless of the described expression of their receptors in HUVECs (16).

\section{Effects of CS-FBS on metabolic activity and cell number}

Our results suggest that the decrease in metabolic activity and cell number observed in HUVECs cultured in ChM was not related to the lack of sex hormones. Moreover, since HUVECs cultured in 199 medium w/out phenol red supplemented with $10 \%$ normal FBS (SM w/out phenol red) did not show any difference in MTT absorbance when compared to HUVECs grown in SM (Fig. 3A), we also excluded the involvement of phenol red and of its estrogenic properties (10). Consequently, we focused our attention on FBS by comparing cells grown in SM with cells cultured in 199 medium containing phenol red and $10 \%$ CSFBS (ChM w/phenol red). Importantly, we submit to the stripping procedure exactly the same lot of serum present in SM. Therefore, in this experimental setting, HUVECs were exposed to growth media that differ only for FBS components. The presence of CS-FBS was sufficient to induce a significant decrease in cell number (Fig. 3B) and MTT absorbance (Fig. 3C). Again, the addition of E2 (1 nM) did not counteract the loss in MTT and ATP induced by CS-FBS (Fig. 3D). Similarly, DHT was unable to reverse the MTT inhibition observed in the presence of CS-FBS when added alone or in combination with E2 (data not shown). Results obtained with ChM w/phenol red suggest that one or more substances removed from FBS by stripping procedure and different from sex hormones are crucially required for HUVEC growth.

\section{Effect of CS-FBS on in vitro angiogenesis}

Among growth factors, Vascular Endothelial Growth Factor (VEGF) and basic Fibroblast Growth Factor (bFGF) are critically involved in EC physiology, being able to induce their growth, migration and in vitro differentiation (17). We therefore tested if VEGF $(20 \mathrm{ng} / \mathrm{ml})$ and bFGF $(20 \mathrm{ng} / \mathrm{ml})$ were able to reverse the inhibitory effect of CS-FBS. The decrease in MTT was however maintained in the presence of the growth factors (Fig. 4A), thus suggesting that neither VEGF nor bFGF were the substance(s) lost in CS-FBS crucially 
required for HUVEC growth. Furthermore, we set up a 3-D assay by embedding size- and cell number-defined HUVEC spheroids in a collagen gel to study in vitro angiogenesis (14, 15). In this assay, spheroids fully retained their ability to sprout when suspended in SM (Figs. 4B, and 4C for quantification) whereas the outgrowth of capillary-like structures was significantly reduced in spheroids suspended in ChM w/phenol red or ChM (Figs. 4B, and 4C for quantification). These results demonstrate that EC growth and sprouting critically require some serum components different from VEGF and bFGF that are lost in CS-FBS.

\section{Discussion}

We started our experiments with the aim of studying the regulatory role of estrogens on metabolic properties in human ECs. But we found that HUVECs underwent a significant decrease in cell number (and consequently in metabolic activity) when cultured in a medium supplemented with CS-FBS commonly used for in vitro studies on hormone activities. Notably, ECs also lacked the ability to undergo in vitro angiogenesis in a 3-D spheroid assay. These results advise about the disregarded contribute of CS-FBS to data obtained from ECs cultured in nominally hormone-free media.

Charcoal-stripped serum is largely used in cellular, biological, and pharmacological studies. The stripping procedure reduces or depletes the concentration of many biologically active substances such as steroids, thyroid and peptide hormones, vitamins, electrolytes, enzymes, metabolites, and lipids $(11,12,18)$. Some alterations in cell signaling and differentiation have been described in cells cultured in CS-FBS in comparison to their counterpart grown in normal serum $(19,20)$. Furthermore, the growth of human CFU-megacaryokytes is improved when cells are cultured in CS-FBS (21) whereas the mouse osteoblastic cell line MC3T3-E1 displays a limited growth and an impaired alkaline phosphatase expression in CS-FBS (22). Again, CS serum modifies the phospholipid metabolism in type II rat pneumocytes (18) and the cellular bioenergetics of breast cancer cells (23). 
Regarding ECs, various results describing the effects of sex hormones on their behavior have been obtained in cells cultured in media supplemented with CS-FBS. However, most of these studies did not refer to cell proliferation even if they involved cells grown in CS-FBS for at least 24-48 $\mathrm{h}(24,25)$ and also when hormones different from estrogens were studied $(26,27)$. To our knowledge, up to now no data are available on the direct comparison of ECs grown in normal or CS-FBS. In our experiments, we consistently observed a reduced EC growth when CS-FBS was used, irrespective of the presence of steroid hormones and phenol red. Very importantly, the presence of CS-FBS totally abrogates the ability of HUVEC spheroids to sprout, thus affecting a functional property distinctive of ECs. Further studies will be necessary to clarify if the inhibitory effect of CS-FBS on sprouting depends on the reduced cell growth and/or on a decrease in the invasive capacity of ECs. But it is important to highlight that a crucial feature of ECs is missed when they are cultured in CS-FBS.

Our data therefore suggest that one or possible more substances removed from FBS are crucial for the maintenance of in vitro EC distinctive properties. This hypothesis is strongly supported by the result showing that the re-addition of normal serum totally restores the metabolic activity of HUVECs previously grown in CS-FBS. Experiments are ongoing in our laboratory in the attempt to identify which of the various substances reduced or depleted from serum by charcoal treatment might have a role in the observed effects. Candidates are quite numerous and heterogeneous. Folic acid and vitamin B12 for example are reduced in CS-FBS, and exert an in vitro protective effect on ECs $(28,29)$. However, a key candidate might be thyroid hormone ( $\mathrm{TH}$, L-thyroxine, $\mathrm{T}_{4} ;$ 3,5, 3'-triiodo-Ithyronine, $\mathrm{T}_{3}$ ). TH plays a central role in the regulation of angiogenesis (30) by acting as soluble ligand on its receptor on integrin av $\beta 3$ that is highly expressed on the membrane of activated ECs. Multiple mechanisms are responsible for the pro-angiogenic effect of TH including modulation of activities of different growth factor receptors and ligands, such as VEGF and bFGF, as well as of angiogenic chemokines. TH also increases the activity of other peptides that contribute to vessel formation such as bradikinin and angiotensin II. 
Furthermore, since non-genomic actions initiated by the binding of TH to its receptor on integrin av $\beta 3$ can finally induce expression of genes involved in angiogenesis, both nongenomic and genomic mechanisms contribute to the pro-angiogenic properties of TH (31). Therefore, the absence of TH from CS-FBS might be critical for the impaired growth and sprouting induced by the hormone-deprived serum in ECs, thus suggesting TH as an excellent candidate to explain our results. Finally, metabolic pathways are emerging as important regulators of angiogenesis. In particular, ECs increase glycolysis while forming new blood vessels (32), and fatty acids have been crucially involved in the regulation of EC proliferation (33). Therefore, also a deficit in cell metabolism might contribute to the impairment of cell growth and sprouting that we observe in ECs grown in CS-FBS.

In conclusion, our data showing that HUVECs lose a distinguishing feature (the sprouting ability) and modify their physiology in the presence of CS-FBS demonstrate the crucial role of media composition in the establishment of cellular responses. These observations may be part of a more general discussion on serum starvation and on its interfering potential with experimental results and conclusions (34). In addition to impart extra variables to experiments, the use of treated sera may also induce unpredictable changes in cellular phenotypic characteristics. For that reason, it is important to be aware of the underestimated contribute that CS-FBS may give to experimental outcomes in ECS, and possibly in other cell types.

\section{Funding}

This work was partly supported by the Dept of Medical Biotechnology and Translational Medicine, University of Milano (Piano Sviluppo Linea B, grant numbers 15-6-3003005-14 to MGC).

\section{Declaration of interest}

The authors report no conflicts of interest. The authors alone are responsible for the content and writing of the paper.

\section{Acknowledgements}

We thank Drs. Donatella Lattuada for FACS analysis and Silvia Bini for HUVEC isolation, 
and all the nurses of the Macedonio Melloni Hospital for helping in the umbilical cord collection.

\section{References}

1. Regitz-Zagrosek $\mathrm{V}$. Therapeutic implications of the gender-specific aspects of cardiovascular disease. Nat Rev Drug Discov 2006; 5: 425-438

2. McDermott BJ, Gray GA. Biological sex themed section: incorporating the female dimension into cardiovascular pharmacology. $\mathrm{Br}$ J Pharmacol 2014; 171: 537-540

3. Li H, Förstermann U. Uncoupling of endothelial NO synthase in atherosclerosis and vascular disease. Curr Opin Pharmacol 2013; 13: 161-167

4. Siti HN, Kamisah Y, Kamsiah J. The role of oxidative stress, antioxidants and vascular inflammation in cardiovascular disease (a review). Vascul Pharmacol $2015 ; 71: 40-56$

5. Rubanyi GM, Kauser K, Johns A. Role of estrogen receptors in the vascular system. Vascul Pharmacol 2002; 38: 81-88

6. Arnal JF, Fontaine C, Billon-Galés A, Favre J, Laurell H, Lenfant F, Gourdy P. Estrogen receptors and endothelium. Arterioscler Thromb Vasc Biol 2010; 30: $1506-1512$

7. Hayashi T, Yamada K, Esaki T, Kuzuya M, Satake S, Ishikawa T, Hidaka H, Iguchi A. Estrogen increases endothelial nitric oxide by a receptor-mediated system. Biochem Biophys Res Commun 1995; 214: 847-855

8. Kleinert $\mathrm{H}$, Wallerath $\mathrm{T}$, Euchenhofer $\mathrm{C}$, Ihrig-Biedert I, Li H, Förstermann U. Estrogens increase transcription of the human endothelial NO synthase gene: analysis of the transcription factors involved. Hypertension $1998 ; 31: 582-588$

9. Haynes MP, Sinha D, Russell KS, Collinge M, Fulton D, Morales-Ruiz M, Sessa WC, Bender JR. Membrane estrogen receptor engagement activates endothelial nitric oxide synthase via the PI3-kinase-Akt pathway in human endothelial cells. Circ Res 2000; 87: 677-682

10. Berthois $\mathrm{Y}$, Katzenellenbogen JA, Katzenellenbogen BS. Phenol red in tissue culture 
media is a weak estrogen: implications concerning the study of estrogenresponsive cells in culture. Proc Natl Acad Sci U S A 1986; 83: 2496-2500

11. R.E. Leake, R.I. Freshnet, I. Munir, in: B. Green, R.E. Leake (Eds.), Steroid hormones - a practical approach, Irl Press, Oxford, 1987, pp 213-214

12. Cao Z, West C, Norton-Wenzel CS, Rej R, Davis FB, Davis PJ. Effects of resin or charcoal treatment on fetal bovine serum and bovine calf serum. Endocr Res 2009; 34: $101-108$

13. Jaffe EA, Nachman RL, Becker CG, Minick CR. Culture of human endothelial cells derived from umbilical veins. Identification by morphologic and immunologic criteria. J Clin Invest 1973; 52: 2745-2756

14. Cappellini E, Vanetti C, Vicentini LM, Cattaneo MG. Silencing of Eps8 inhibits in vitro angiogenesis. Life Sci 2015; 131: 30-36

15. Heiss $M$, Hellström $M$, Kalén $M$, May $T$, Weber $H$, Hecker $M$, Augustin HG, Korff T. Endothelial cell spheroids as a versatile tool to study angiogenesis in vitro. FASEB J $2015 ; 29: 3076-3084$

16. Addis R, Campesi I, Fois M, Capobianco G, Dessole S, Fenu G, Montella A, Cattaneo MG, Vicentini LM, Franconi F. Human umbilical endothelial cells (HUVECs) have a sex: characterisation of the phenotype of male and female cells. Biol Sex Differ $2014 ; 5: 18$

17. Cross MJ, Claesson-Welsh L. FGF and VEGF function in angiogenesis: signalling pathways, biological responses and therapeutic inhibition. Trends Pharmacol Sci $2001 ; 22: 201-207$

18. Viscardi RM, Ullsperger S, McKenna MC. Carbon stripping extracts serum free fatty acids: implications for media supplementation of cultured type II pneumocytes. Lab Invest 1991; 65: 250-257

19. Tso CL, McBride WH, Sun J, Patel B, Tsui KH, Paik SH, Gitlitz B, Caliliw R, van Ophoven A, Wu L, deKernion J, Belldegrun A. Androgen deprivation induces selective outgrowth of aggressive hormone-refractory prostate cancer clones 
expressing distinct cellular and molecular properties not present in parental androgen-dependent cancer cells. Cancer J 2000; 6: 220-233

20. Dang ZC, Lowik CW. Removal of serum factors by charcoal treatment promotes adipogenesis via a MAPK-dependent pathway. Mol Cell Biochem 2005; 268: 159167

21. Lindquist $\mathrm{DL}$, de Alarcon PA. Charcoal-dextran treatment of fetal bovine serum removes an inhibitor of human CFU-megakaryocytes. Exp Hematol 1987; 15: 234238

22. Yohay DA, Zhang J, Thrailkill KM, Arthur JM, Quarles LD. Role of serum in the developmental expression of alkaline phosphatase in MC3T3-E1 osteoblasts. J Cell Physiol 1994; 158: 467-475

23. Radde BN, Ivanova MM, Mai HX, Salabei JK, Hill BG, Klinge CM. Bioenergetic differences between MCF-7 and T47D breast cancer cells and their regulation by oestradiol and tamoxifen. Biochem J 2015; 465: 49-61

24. Simoncini T, Fornari L, Mannella P, Varone G, Caruso A, Garibaldi S, Genazzani AR. Differential estrogen signaling in endothelial cells upon pulsed or continuous administration. Maturitas 2005; 50: 247-258

25. Sobrino A, Mata M, Laguna-Fernandez A, Novella S, Oviedo PJ, García-Pérez MA, Tarín JJ, Cano A, Hermenegildo C. Estradiol stimulates vasodilatory and metabolic pathways in cultured human endothelial cells. PLoS One 2009; 4: e8242

26. Goglia L, Tosi V, Sanchez AM, Flamini MI, Fu XD, Zullino S, Genazzani AR, Simoncini T. Endothelial regulation of eNOS, PAI-1 and t-PA by testosterone and dihydrotestosterone in vitro and in vivo. Mol Hum Reprod 2010; 16: 761-769

27. Lee TS, Lin JJ, Huo YN, Lee WS. Progesterone Inhibits Endothelial Cell Migration Through Suppression of the Rho Activity Mediated by cSrc Activation. J Cell Biochem 2015; 116: 1411-1418

28. van der Molen EF, van den Heuvel LP, te Poele Pothoff MT, Monnens IA, Eskes TK, Blom $\mathrm{HJ}$. The effect of folic acid on the homocysteine metabolism in human 
umbilical vein endothelial cells (HUVECs). Eur J Clin Invest 1996; 26: 304-309

29. Moreira ES, Brasch NE, Yun J. Vitamin B12 protects against superoxide-induced cell injury in human aortic endothelial cells. Free Radic Biol Med 2011; 51: 876-883

30. Mousa SA, Lin H-Y, Tang HY, Hercbergs A, Luidens MK, Davis PJ. Modulation of angiogenesis by thyroid hormone and hormone analogues: implications for cancer management. Angiogenesis 2014; 17: 463-469

31. Hammes SR, Davis PJ. Overlapping non genomic and genomic actions of thyroid hormone and steroids. Best Pract Res Clin Endocrinol Metab 2015; 29: 581-593

32. De Bock K, Georgiadou M, Schoors S, Kuchnio A, Wong BW, Cantelmo AR, Quaegebeur A, Ghesquière B, Cauwenberghs S, Eelen G, Phng LK, Betz I, Tembuyser B, Brepoels K, Welti J, Geudens I, Segura I, Cruys B, Bifari F, Decimo I, Blanco R, Wyns S, Vangindertael J, Rocha S, Collins RT, Munck S, Daelemans D, Imamura H, Devlieger R, Rider M, Van Veldhoven PP, Schuit F, Bartrons R, Hofkens J, Fraisl P, Telang S, Deberardinis RJ, Schoonjans L, Vinckier S, Chesney J, Gerhardt H, Dewerchin M, Carmeliet P. Role of PFKFB3-driven glycolysis in vessel sprouting. Cell 2013; 154:651-663

33. Schoors S, Bruning U, Missiaen R, Queiroz KC, Borgers G, Elia I, Zecchin A, Cantelmo AR, Christen S, Goveia J, Heggermont W, Goddé L, Vinckier S, Van Veldhoven PP, Eelen G, Schoonjans L, Gerhardt H, Dewerchin M, Baes M, De Bock K, Ghesquière B, Lunt SY, Fendt SM, Carmeliet P. Fatty acid carbon is essential for dNTP synthesis in endothelial cells. Nature 2015; 520: 192-197

34. Pirkmajer S, Chibalin AV. Serum starvation: caveat emptor. Am J Physiol Cell Physiol 2011; 301: C272-279

\section{Legends to figures}


Figure 1. Hormone deprivation induces a decrease in metabolic activity and cell number. HUVECs were cultured in SM (solid bars) or ChM (open bars), and 48h later fresh media were added. MTT absorbance (A), total cellular ATP (B), and cell number (C) were measured after further $48 \mathrm{~h}$ of incubation. ${ }^{*} \mathrm{p}<0.05$ vs $\mathrm{SM}, \mathrm{n}=4-6-3$ in (A), (B), and (C), respectively. (D) FACS analysis using Annexin V/PI double staining. Percents of gated cells in each quadrant are shown $(n=4)$. UL, necrotic cells; UR + LR, apoptotic cells; $\mathrm{LL}$, live cells.

Figure 2. Sex hormones do not reverse the loss in metabolic activity and cell number. Experiments were performed as described in Figure 1 on HUVECs cultured for $48 \mathrm{~h}$ in SM or ChM. During the last $48 \mathrm{~h}$ of incubation, media were changed, and cells in ChM were treated with vehicle (ethanol, open bars) or E2 (1 nM, diagonal bars) before measurements of MTT (A), ATP (B), and cell number (C). Data are expressed as percentages of control cells i.e. cells cultured in SM (solid bar). $* * * p<0.001, * * p<0.01$, ${ }^{*} \mathrm{p}<0.05$ vs SM, ns vs ChM + vehicle, $\mathrm{n}=9-5-3$ in (A), (B), and (C), respectively. In (D), vehicle (open bar), E2 (1 nM, diagonal bar), DHT (1 nM, horizontal bar), or E2 + DHT (grey bar) were added to ChM as described above. **p<0.001 vs SM, ns vs ChM + vehicle, $n=3$. (E) ChM was replaced with $S M$ for the last $48 \mathrm{~h}$ of incubation (ChM/SM, squared bar). ${ }^{* * *} \mathrm{p}<0.001$ vs $\mathrm{SM},{ }^{\circ 00} \mathrm{p}<0.001$ vs ChM, $\mathrm{n}=3$.

Figure 3. CS-FBS is sufficient to induce a decrease in metabolic activity and cell number. (A) MTT absorbance was measured after $48 \mathrm{~h}$ of incubation in SM (solid bar) or SM w/out phenol red (pointed bar). ns vs SM, $\mathrm{n}=7$. Cell number (B) and MTT (C) were measured after $48 \mathrm{~h}$ of incubation in SM (solid bars), ChM w/phenol red (cross-hitched bars) or ChM (open bars). ${ }^{*} p<0.05, * * p<0.01$ vs $S M$, no significant differences between ChM w/phenol red and ChM, One-way ANOVA with Bonferroni's test, $n=4-10$ in (B) and (C), respectively. (D) MTT (left axis) and ATP (right axis) were measured after $48 \mathrm{~h}$ of incubation in SM (solid bars), in ChM w/phenol red + vehicle (cross-hitched bars), or in ChM w/phenol red + E2 (1 nM, diagonal bars). ${ }^{*} \mathrm{p}<0.05$ vs SM, ns vs ChM + vehicle, $\mathrm{n}=3$. 
Figure 4. Effect of CS-FBS on in vitro angiogenesis. (A) HUVECs were cultured for $48 \mathrm{~h}$ in SM (solid bars), ChM w/phenol red (cross-hitched bars) or ChM (open bar) in the absence or in the presence of VEGF and bFGF (both at $20 \mathrm{ng} / \mathrm{ml}$ ). $* * * p<0.001$ vs SM, ns vs ChM w/phenol red or ChM, $\mathrm{n}=3$. (B) Representative images of HUVEC spheroids embedded in collagen gels in the presence of SM (upper panel), ChM w/phenol red (middle panel) or ChM (lower panel). Photographs were taken $24 \mathrm{~h}$ later. (C) Quantification of the number of sprouts (left axis) and of the cumulative sprouting length (right axis) emerging from 12-15 individual spheroids per experimental group in a representative experiment repeated three times. $* * * p<0.001$ vs SM, One-way ANOVA with Bonferroni's test. 

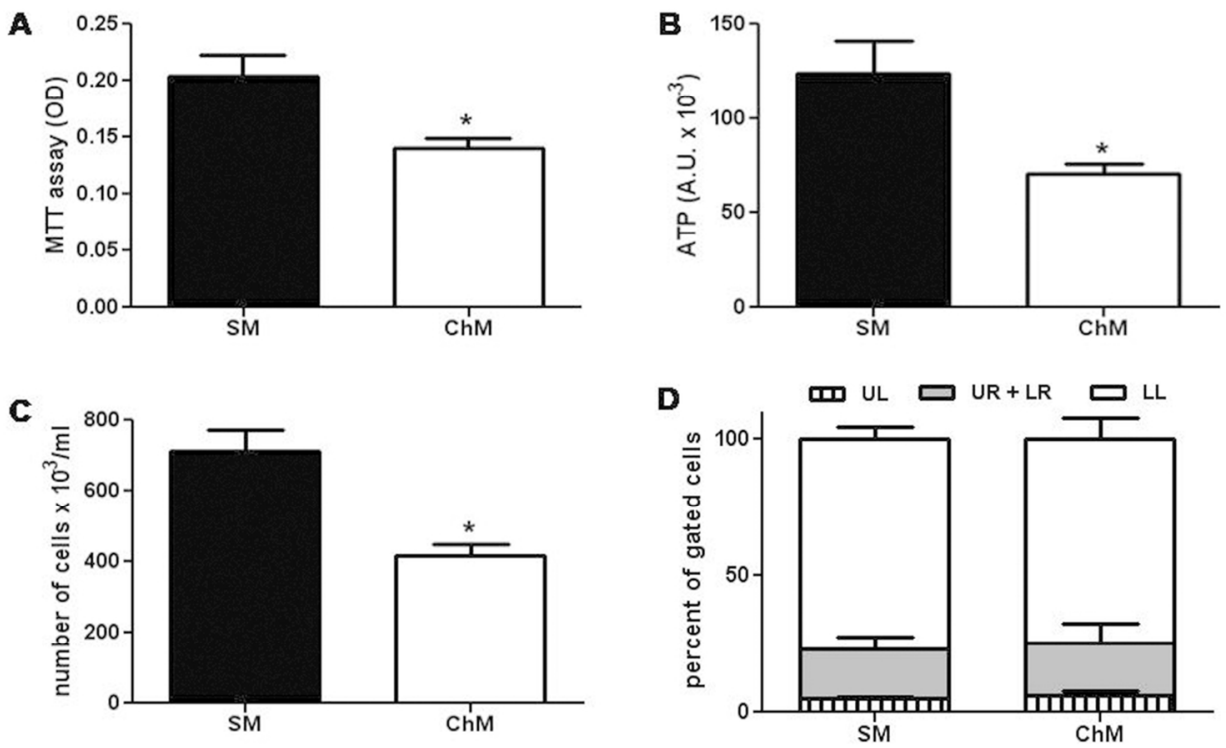

Figure 1. Hormone deprivation induces a decrease in metabolic activity and cell number. HUVECS were cultured in SM (solid bars) or ChM (open bars), and 48h later fresh media were added. MTT absorbance (A), total cellular ATP $(B)$, and cell number $(C)$ were measured after further $48 \mathrm{~h}$ of incubation. $* p<0.05$ vs SM, $n=4-6-3$ in (A), (B), and (C), respectively. (D) FACS analysis using Annexin V/PI double staining. Percents of gated cells in each quadrant are shown $(n=4)$. UL, necrotic cells; UR + LR, apoptotic cells; LL, live cells. $108 \times 68 \mathrm{~mm}(300 \times 300$ DPI $)$ 
A

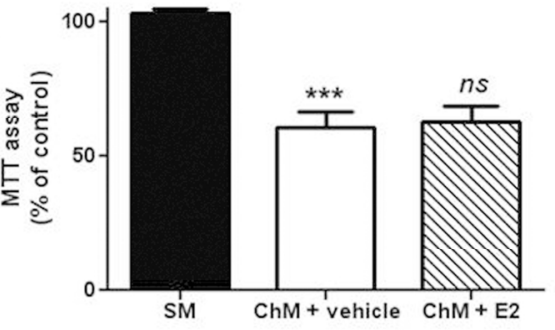

B
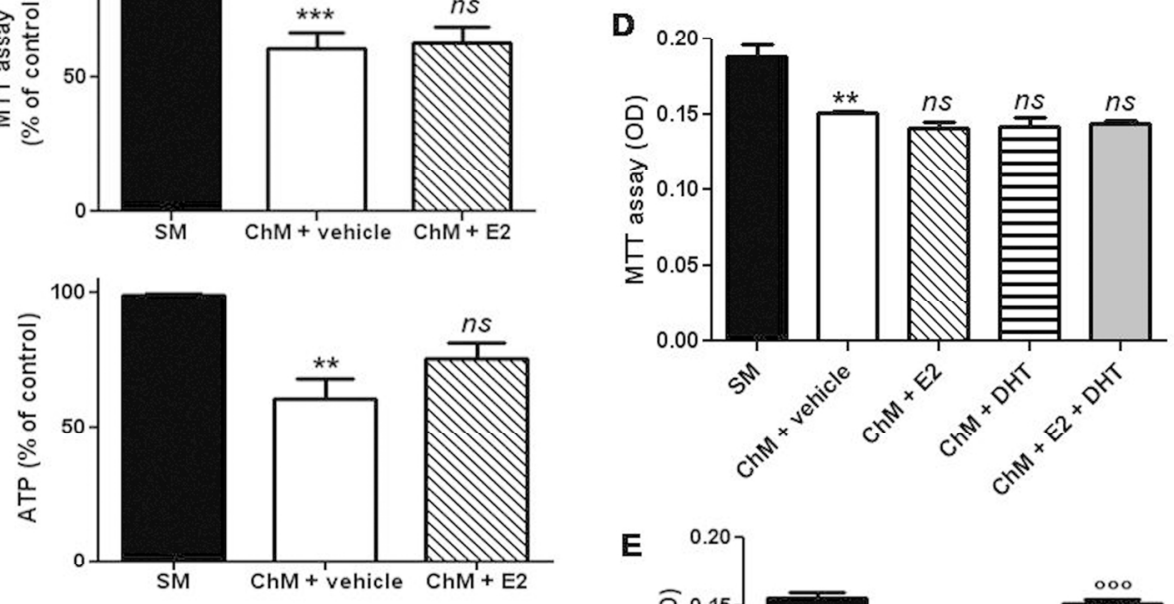

C
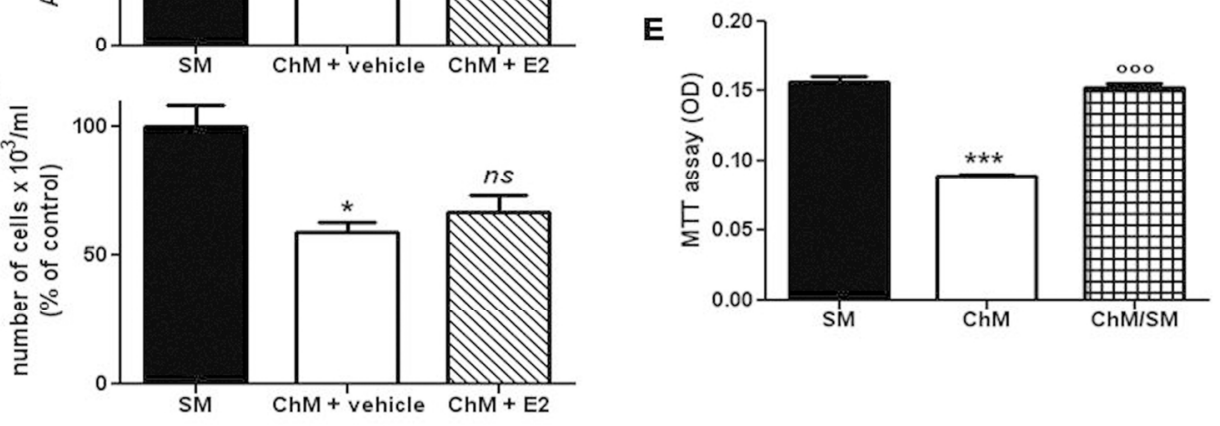

Figure 2. Sex hormones do not reversed the loss in metabolic activity and cell number. Experiments were performed as described in Figure 1 on HUVECs cultured for $48 \mathrm{~h}$ in SM or ChM. During the last $48 \mathrm{~h}$ of incubation, media were changed, and cells in ChM were treated with vehicle (ethanol, open bars) or E2 (1 $\mathrm{nM}$, diagonal bars) before measurements of MTT (A), ATP (B), and cell number (C). Data are expressed as percentages of control cells i.e. cells cultured in SM (solid bar). $* * * p<0.001, * * p<0.01, * p<0.05$ vs SM, ns vs ChM + vehicle, $n=9-5-3$ in (A), (B), and (C), respectively. In (D), vehicle (open bar), E2 (1 nM, diagonal bar), DHT (1 nM, horizontal bar), or E2 + DHT (grey bar) were added to ChM as described above. $* * p<0.001$ vs $S M, n s$ vs $C h M+$ vehicle, $n=3$. (E) ChM was replaced with SM for the last $48 \mathrm{~h}$ of incubation (ChM/SM, squared bar). ${ }^{* * *} \mathrm{p}<0.001$ vs SM, $\square \square \mathrm{p}<0.001$ vs ChM, $\mathrm{n}=3$. $139 \times 112 \mathrm{~mm}(300 \times 300 \mathrm{DPI})$ 
A
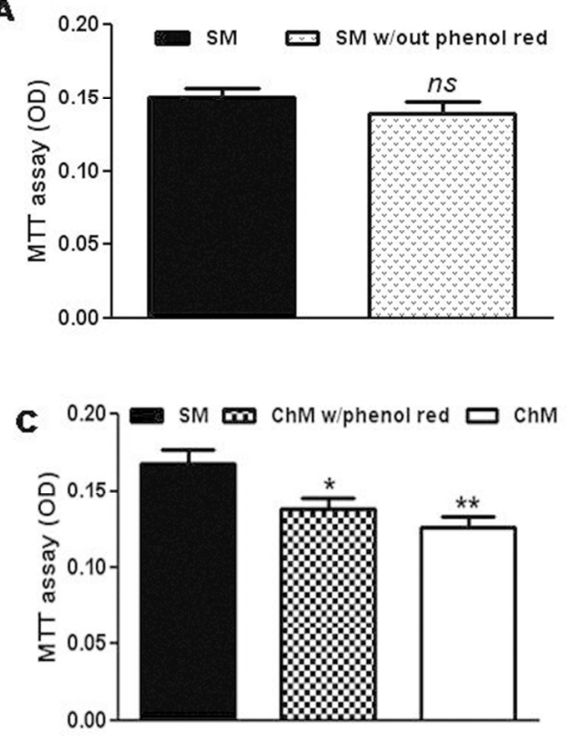

B
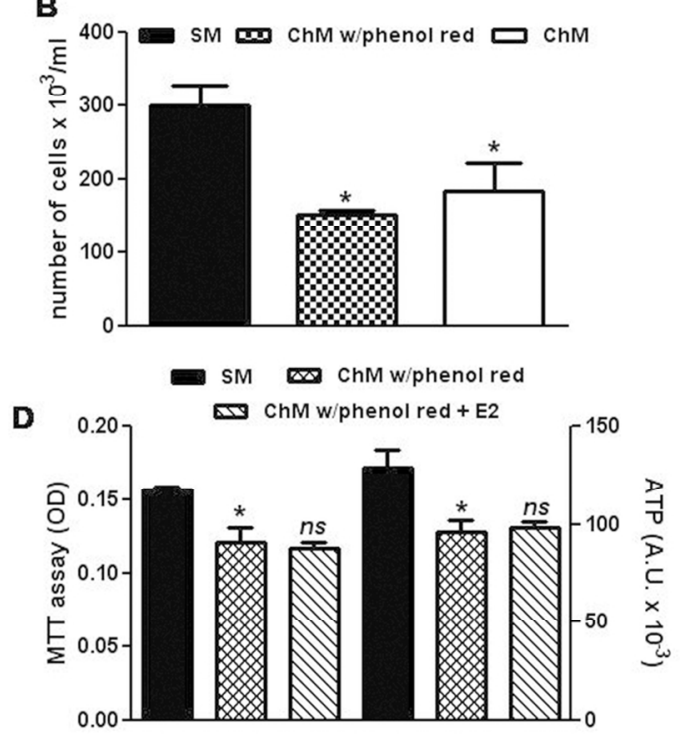

Figure 3. CS-FBS is sufficient to induce a decrease in metabolic activity and cell number. (A) MTT absorbance was measured after $48 \mathrm{~h}$ of incubation in SM (solid bar) or SM w/out phenol red (pointed bar). ns vs SM, $n=7$. Cell number (B) and MTT (C) were measured after $48 \mathrm{~h}$ of incubation in SM (solid bars), ChM $\mathrm{w} /$ phenol red (cross-hitched bars) or ChM (open bars). ${ }^{*} p<0.05, * * p<0.01$ vs SM, no significant differences between ChM w/phenol red and ChM, One-way ANOVA with Bonferroni's test, $n=4-10$ in (B) and (C), respectively. (D) MTT (left axis) and ATP (right axis) were measured after $48 \mathrm{~h}$ of incubation in SM (solid bars), in ChM w/phenol red + vehicle (cross-hitched bars), or in ChM w/phenol red + E2 (1 nM, diagonal bars). ${ }^{*} \mathrm{p}<0.05$ vs $\mathrm{SM}, \mathrm{ns}$ vs ChM + vehicle, $\mathrm{n}=3$. $104 \times 63 \mathrm{~mm}(300 \times 300 \mathrm{DPI})$ 


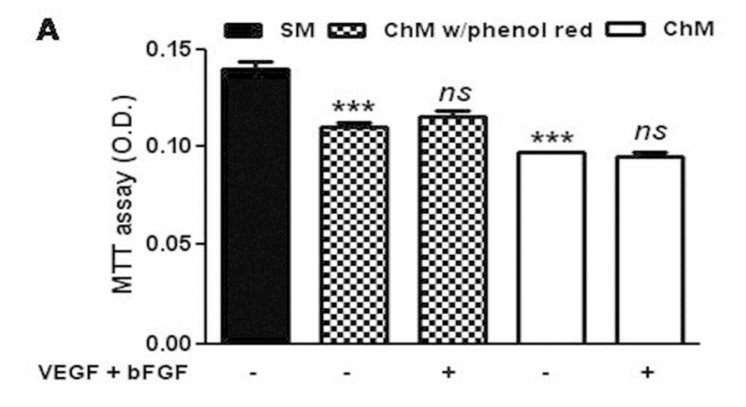

B

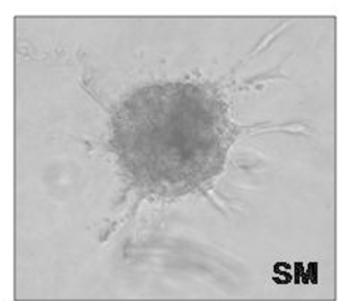

c
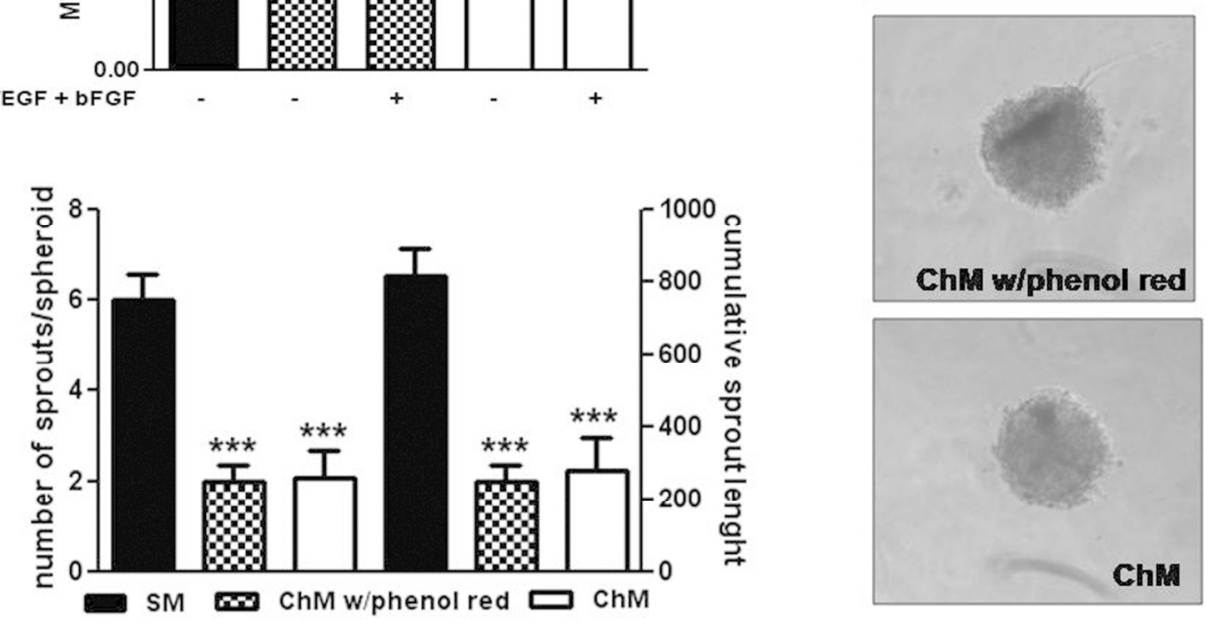

Figure 4. Effect of CS-FBS on in vitro angiogenesis. (A) HUVECs were cultured for 48h in SM (solid bars), $\mathrm{ChM}$ w/phenol red (cross-hitched bars) or ChM (open bar) in the absence or in the presence of VEGF and bFGF (both at $20 \mathrm{ng} / \mathrm{ml}$ ). $* * * p<0.001$ vs SM, ns vs ChM w/phenol red or ChM, n=3. (B) Representative images of HUVEC spheroids embedded in collagen gels in the presence of SM (upper panel), ChM w/phenol red (middle panel) or ChM (lower panel). Photographs were taken $24 \mathrm{~h}$ later. (C) Quantification of the number of sprouts (left axis) and of the cumulative sprouting length (right axis) emerging from 12-15 individual spheroids per experimental group in a representative experiment repeated three times. $* * * p<0.001$ vs SM, One-way ANOVA with Bonferroni's test. $128 \times 95 \mathrm{~mm}(300 \times 300 \mathrm{DPI})$ 